\title{
Transmitral Doppler Flow Pattern in Left Atrial Myxoma
}

\author{
Mareomi Hamada ${ }^{1}$, Akiyoshi Ogimoto ${ }^{1}$ and Yuji Shigematsu ${ }^{2}$
}

Key words: Left atrial myxoma, Transmitral Doppler flow

(Intern Med 57: 2093-2094, 2018)

(DOI: 10.2169/internalmedicine.0456-17)
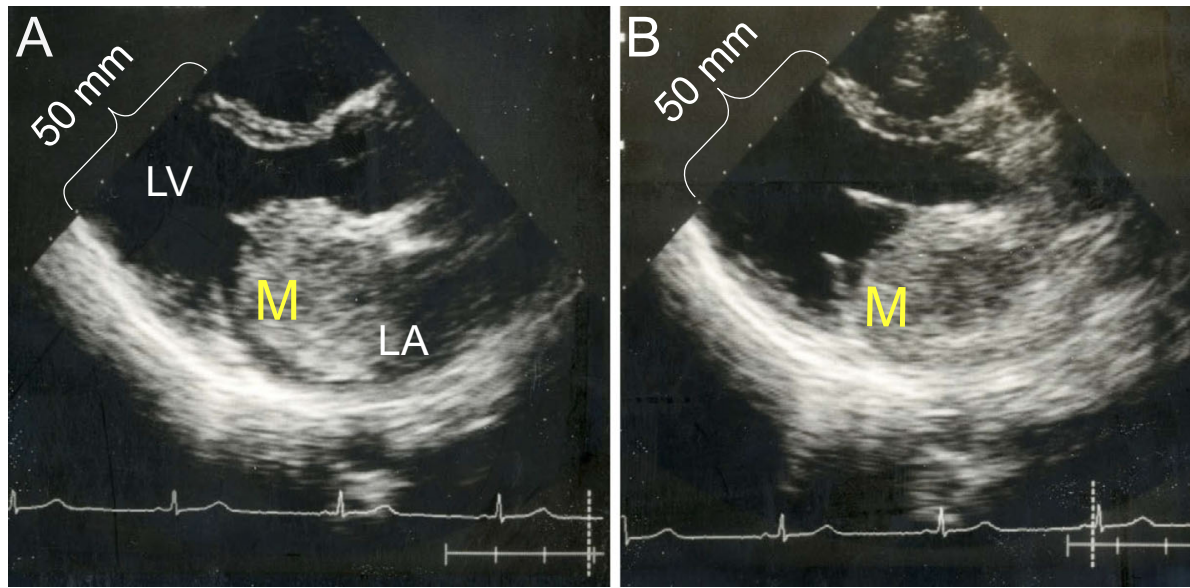

Picture 1.

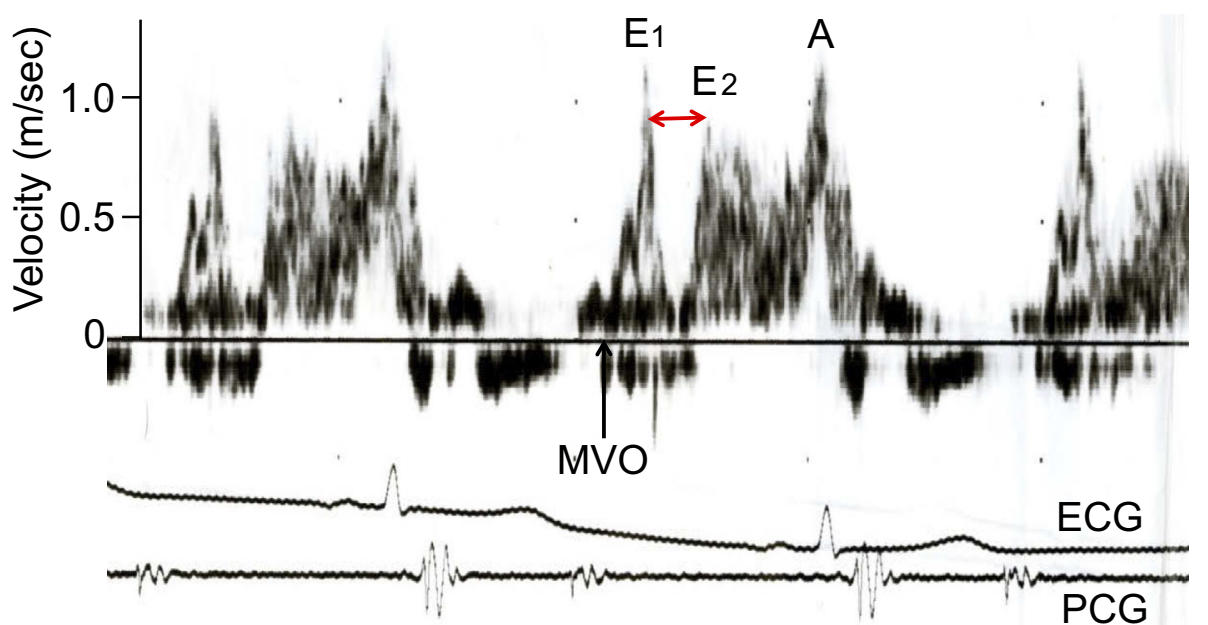

Picture 2.

A 36-year-old woman presented to our hospital with chest discomfort. The electrocardiography findings were within normal limits. Echocardiography indicated a giant mass due to myxoma (M) in the left atrium (LA) (Picture 1). The myxoma plopped into the mitral orifice early in the diastolic phase (Picture 1-A), and remained almost immobile, even

${ }^{1}$ Division of Cardiology, Uwajima City Hospital, Japan and ${ }^{2}$ Fundamental and Clinical Nursing, Ehime University Graduate School of Medicine, Japan

Received: November 7, 2017; Accepted: December 1, 2017; Advance Publication by J-STAGE: February 28, 2018

Correspondence to Dr. Mareomi Hamada, mareomi.hamada@gmail.com 


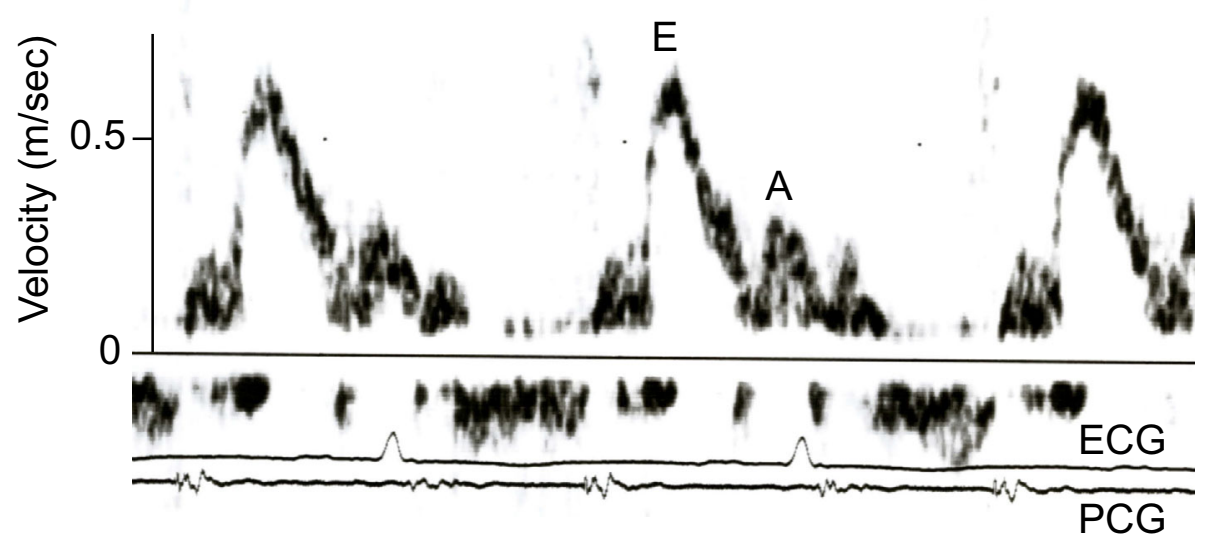

Picture 3.

during late diastole (Picture 1-B). A transmitral Doppler flow examination showed a unique pattern (Picture 2). After mitral valve opening (MVO), we observed an inflow of blood from the LA into the left ventricle (LV)(E1-wave). However, the inflow of blood ceased immediately thereafter. After a pause of approximately 100-120 ms (shown by a red arrow), the inflow resumed (E2).

The myxoma $(52 \times 43 \mathrm{~mm})$ was removed, and the echocardiographic abnormalites returned to normal (Picture 3). We conclude that the large-size of the myxoma might have been the reason for the unique transmitral Doppler flow pattern.

The authors state that they have no Conflict of Interest (COI).

The Internal Medicine is an Open Access article distributed under the Creative Commons Attribution-NonCommercial-NoDerivatives 4.0 International License. To view the details of this license, please visit (https://creativecommons.org/licenses/ by-nc-nd/4.0/).

(C) 2018 The Japanese Society of Internal Medicine Intern Med 57: 2093-2094, 2018 